University of Wollongong

Research Online

Australian Institute for Innovative Materials -

Papers

Australian Institute for Innovative Materials

$1-1-2013$

Thermolysis and solid state NMR studies of $\mathrm{NaB3H} 8, \mathrm{NH} 3 \mathrm{~B} 3 \mathrm{H} 7$, and $\mathrm{NH} 4 \mathrm{~B} 3 \mathrm{H} 8$

Zhenguo Huang

University of Wollongong, zhenguo@uow.edu.au

Mitch Eagles

Washington University

Spencer Porter

University of Wollongong, sp733@uowmail.edu.au

Eric G. Sorte

Washington University

Beau Billet

Ohio State University

See next page for additional authors

Follow this and additional works at: https://ro.uow.edu.au/aiimpapers

Part of the Engineering Commons, and the Physical Sciences and Mathematics Commons

Research Online is the open access institutional repository for the University of Wollongong. For further information contact the UOW Library: research-pubs@uow.edu.au 


\title{
Thermolysis and solid state NMR studies of NaB3H8, NH3B3H7, and NH4B3H 8
}

\begin{abstract}
In an effort to broaden the search for high-capacity hydrogen storage materials, three triborane compounds, $\mathrm{NaB} 3 \mathrm{H} 8, \mathrm{NH} 3 \mathrm{~B} 3 \mathrm{H} 7$, and $\mathrm{NH} 4 \mathrm{~B} 3 \mathrm{H}$ 8, were studied. In addition to hydrogen, thermal decomposition also releases volatile boranes, and the relative amounts and species depend on the cations $(\mathrm{Na}+, \mathrm{NH} 4+$ ) and the Lewis base (NH 3). Static-sample hydrogen NMR is used to probe molecular motion in the three solids. In each case, the line width decreases from low temperatures to room temperature in accordance with a model of isotropic or nearly isotropic reorientations. Such motions also explain a deep minimum in the relaxation time T1. Translational diffusion never appears to be rapid on the $10-5$ s time scale of NMR.
\end{abstract}

\section{Keywords}

thermolysis, nh4b3h, solid, 8, state, nmr, studies, nab3h8, nh3b3h7

Disciplines

Engineering | Physical Sciences and Mathematics

\section{Publication Details}

Huang, Z., Eagles, M., Porter, S., Sorte, E. G., Billet, B., Corey, R. L., Conradi, M. S. \& Zhao, J. C. (2013). Thermolysis and solid state NMR studies of $\mathrm{NaB3H} 8, \mathrm{NH} 3 \mathrm{~B} 3 \mathrm{H} 7$, and NH4B3H 8. Dalton Transactions: an international journal of inorganic chemistry, 42 (3), 701-708.

\section{Authors}

Zhenguo Huang, Mitch Eagles, Spencer Porter, Eric G. Sorte, Beau Billet, Robert L. Corey, Mark S. Conradi, and Ji-Cheng Zhao 


\title{
Thermolysis and solid state NMR studies of $\mathrm{NaB}_{3} \mathrm{H}_{8}, \mathrm{NH}_{3} \mathrm{~B}_{3} \mathrm{H}_{7}$, and $\mathrm{NH}_{4} \mathrm{~B}_{3} \mathrm{H}_{8}$
}

\author{
Zhenguo Huang, ${ }^{a, b, *}$ Mitch Eagles, ${ }^{c}$ Spencer Porter, ${ }^{b}$ Eric G. Sorte, ${ }^{c}$ Beau Billet, ${ }^{a}$ Robert L. Corey, ${ }^{d, c}$ \\ Mark S. Conradi ${ }^{c, *}$ and Ji-Cheng Zhao ${ }^{a, *}$
}

\author{
5 Received (in $X X X, X X X)$ Xth $X X X X X X X X X 20 X X$, Accepted $X$ th $X X X X X X X X X 20 X X$ \\ DOI: 10.1039/b000000x
}

In an effort to broaden the search for high-capacity hydrogen storage materials, three triborane compounds, $\mathrm{NaB}_{3} \mathrm{H}_{8}, \mathrm{NH}_{3} \mathrm{~B}_{3} \mathrm{H}_{7}$, and $\mathrm{NH}_{4} \mathrm{~B}_{3} \mathrm{H}_{8}$, were studied. In addition to hydrogen, thermal decomposition also releases volatile boranes, and the relative amounts and species depend on the cations $10\left(\mathrm{Na}^{+}, \mathrm{NH}_{4}^{+}\right)$and the Lewis base $\left(\mathrm{NH}_{3}\right)$. Static-sample hydrogen NMR is used to probe molecular motion in the three solids. In each case, the line width decreases from low temperatures to room temperature in accordance with a model of isotropic or nearly isotropic reorientations. Such motions also explain a deep minimum in the relaxation time $\mathrm{T}_{1}$. Translational diffusion never appears to be rapid on the $10^{-5} \mathrm{~s}$ time scale of NMR.

\section{${ }_{15}$ Introduction}

Boranes and borohydrides have recently been intensively studied for hydrogen storage since they contain high hydrogen content and can release hydrogen at relatively low temperatures. Ammonia borane $\left(\mathrm{NH}_{3} \mathrm{BH}_{3}\right.$, denoted as $\left.\mathrm{AB}\right)$ and sodium 20 borohydride $\left(\mathrm{NaBH}_{4}\right)$ are arguably the exemplary borane and borohydride, respectively. AB has $19.4 \mathrm{wt} \%$ hydrogen and releases $12 \mathrm{wt} \%$ hydrogen at moderate temperatures $\left(<120{ }^{\circ} \mathrm{C}\right){ }^{1}$ Solid state decomposition of $\mathrm{AB}$, however, suffers from the release of undesirable volatiles and the lack of cost-efficient 25 regeneration. ${ }^{2}$ Even though improved performance in these areas has been reported, ${ }^{3}$ the U.S. Department of Energy (DOE) has shifted the focus from solid state decomposition to $\mathrm{AB}$ slurries for vehicular applications, as they offer advantages such as easy spent-fuel transportation and high hydrogen purity. ${ }^{4}$ The high 30 thermal decomposition temperature $\left(>400{ }^{\circ} \mathrm{C}\right)$ has made $\mathrm{NaBH}_{4}$ impractical as a solid state hydrogen storage medium. ${ }^{5}$ Therefore, $\mathrm{NaBH}_{4}$ has been intensively studied for hydrogen release via hydrolysis. However, the phase change between the starting material and the products has been a key barrier to its application,

35 which is further complicated by the lack of economical reformation from the hydrolytic products. ${ }^{6}$ Among the other borohydrides, lithium and magnesium borohydrides are still attracting attention, and interesting results have been published, especially on regeneration. ${ }^{7,8}$ Effective hydrogen storage is 40 needed beyond automotive applications, and applications such as portable electronics and stationary energy storage have requirements that are different from those for vehicular applications. In these non-vehicular applications, boranes and borohydrides (including $\mathrm{NaBH}_{4}$ ) are promising candidates.

45 In addition to studying commercially available compounds, researchers also direct their attention to other compounds, such as $\mathrm{AlB}_{4} \mathrm{H}_{11},{ }^{9} \mathrm{NH}_{3} \mathrm{~B}_{3} \mathrm{H}_{7},{ }^{10}$ and $\mathrm{NH}_{4} \mathrm{BH}_{4},{ }^{11}$ which have high hydrogen content but lack suitable syntheses. There are actually a variety of boranes and borohydrides. One $\mathrm{BH}$ condensation up on the ladder 50 from $\mathrm{BH}_{3}$ and $\mathrm{BH}_{4}^{-}$is diborane $\left(\mathrm{B}_{2} \mathrm{H}_{6}\right)$; however, its explosive and toxic nature essentially eliminates it from further consideration. Another $\mathrm{BH}$ condensation up is triborane $\left(\mathrm{B}_{3} \mathrm{H}_{7}\right.$ and $\mathrm{B}_{3} \mathrm{H}_{8}{ }^{-}$), which still retains high hydrogen capacity. The synthesis of triborane has been a challenge, however, since it 55 traditionally requires $\mathrm{B}_{2} \mathrm{H}_{6}$ and its isolation is not satisfactory. ${ }^{12}$

$\mathrm{B}_{3} \mathrm{H}_{8}{ }^{-}$has recently been observed during the thermal decomposition of $\mathrm{Mg}\left(\mathrm{BH}_{4}\right)_{2} \cdot{ }^{13}$ Dehydrogenation of $\mathrm{Mg}\left(\mathrm{BH}_{4}\right)_{2}$ at $200{ }^{\circ} \mathrm{C}$ in vacuo results in a highly selective formation of magnesium triborane, $\operatorname{Mg}\left(\mathrm{B}_{3} \mathrm{H}_{8}\right)_{2}$. This process is reversible at $60250{ }^{\circ} \mathrm{C}$ under $120 \mathrm{~atm} \mathrm{H}_{2}$. As the authors stated, this is the first example of a reversible, solid-state rehydrogenation of a borohydride occurring below $350{ }^{\circ} \mathrm{C}$. The importance of studying $\mathrm{B}_{3} \mathrm{H}_{8}{ }^{-}$manifests itself in two main aspects. First, it leads to more options in the search of hydrogen storage materials beyond $\mathrm{BH}_{3}$ 65 and $\mathrm{BH}_{4}{ }^{-}$based materials. Secondly, it provides a fundamental understanding of the mechanisms of thermal decomposition and regeneration, as evidenced by the case of $\mathrm{Mg}\left(\mathrm{BH}_{4}\right)_{2}$.

We have recently reported the syntheses of $\mathrm{NaB}_{3} \mathrm{H}_{8}{ }^{14}$ and $\mathrm{NH}_{4} \mathrm{~B}_{3} \mathrm{H}_{8},{ }^{15}$ and their hydrogen release via hydrolysis. The new 70 synthetic procedures enable safe and efficient syntheses in a typical laboratory. Our studies have shown that these two compounds outperform $\mathrm{NaBH}_{4}$ and $\mathrm{NH}_{3} \mathrm{BH}_{3}$ as hydrogen storage materials via hydrolysis. ${ }^{15,16}$ This paper presents results on thermal decomposition, structural analysis using density 75 functional theory (DFT) calculations, and the nature of molecular motions via static solid-state ${ }^{1} \mathrm{H}$ nuclear magnetic resonance (NMR) spectrometry. The molecular motions in the solid state, 
particularly self-diffusion, may be crucial to the rates of the dehydriding and rehydriding reactions, since solid state reactions generally require the transport of atoms from the surface into the bulk.

\section{${ }_{5}$ Experimental}

\section{General Procedures}

All manipulations were carried out on a high-vacuum line or in a glove box filled with high purity nitrogen. Unsolvated $\mathrm{NaB}_{3} \mathrm{H}_{8}$, $\mathrm{NH}_{3} \mathrm{~B}_{3} \mathrm{H}_{7}$, and $\mathrm{NH}_{4} \mathrm{~B}_{3} \mathrm{H}_{8}$ were prepared according to the 10 published procedures. ${ }^{14,10,15}$ Due to their hygroscopic nature, all compounds were stored and handled under an inert atmosphere except during measurements. Solution NMR spectra were obtained on a Bruker Avance DPX 250 NMR. ${ }^{11} \mathrm{~B}$ NMR spectra were obtained at $80.3 \mathrm{MHz}$ and externally referenced to $\mathrm{BF}_{3} \cdot \mathrm{OEt}_{2}$ 15 in $\mathrm{C}_{6} \mathrm{D}_{6}$ at $0.00 \mathrm{ppm}$.

\section{Thermal decomposition studies}

Thermal stability was investigated using a Mettler Toledo high-pressure differential scanning calorimeter (DSC27HP) in an argon glove box with a ramp rate of $5{ }^{\circ} \mathrm{C} / \mathrm{min}$. 20 Thermogravimetric analysis (TGA) was performed on a Perkin Elmer TGA 7 analyzer. Powder was loaded onto a quartz crucible and heated to $400{ }^{\circ} \mathrm{C}$ at a heating rate of $5{ }^{\circ} \mathrm{C} / \mathrm{min}$ under an $\mathrm{Ar}$ flow of $40 \mathrm{~cm}^{3} / \mathrm{min}$. Mass spectra of the gas released from the thermal decomposition were collected via a Balzer's Quadstar 422 25 quadrupole mass spectrometer. In a separate experiment, $2 \mathrm{mmol}$ $\mathrm{NaB}_{3} \mathrm{H}_{8}$ was loaded into a $50 \mathrm{ml}$ flask that was connected to a vacuum line, where another $50 \mathrm{ml}$ flask filled with $10 \mathrm{~mL}$ anhydrous tetrahydrofuran (THF) was also attached. The THF was cooled to liquid nitrogen temperature, so was solidified, 30 before the flask was opened to dynamic vacuum. After $10 \mathrm{~min}$ dynamic evacuation, the flask with the sample was slowly heated up to $200{ }^{\circ} \mathrm{C}$. The gaseous decomposition products (except for $\mathrm{H}_{2}$ ) were condensed into the flask cooled by liquid nitrogen. The condensed products were then analysed using ${ }^{11} \mathrm{~B}$ NMR 35 spectroscopy. Similar procedures were applied in the case of $\mathrm{NH}_{3} \mathrm{~B}_{3} \mathrm{H}_{7}$ and $\mathrm{NH}_{4} \mathrm{~B}_{3} \mathrm{H}_{8}$. The high sensitivity of ${ }^{11} \mathrm{~B}$ allows for an easy and accurate identification of these $\mathrm{B}$ containing products. In addition, the relative amounts of the volatile products can be analysed based on NMR signal integration.

\section{${ }_{40}$ Solid state NMR analysis}

The solid residue after thermal decomposition was characterized using solid state magnetic angle spinning (MAS) NMR. This was performed in a field of 6.9 Tesla using $5 \mathrm{~mm}$ rotors spinning at $5 \mathrm{kHz}$. Only ${ }^{11} \mathrm{~B}$ was examined, at $94.6 \mathrm{MHz}$ 45 and room temperature. The free induction decays (FIDs) following 3 microsecond $\pi / 2$ rf pulses were signal averaged over about 30 minutes (4000 scans), with high-power hydrogen decoupling. The shift reference was liquid $\mathrm{BF}_{3} \cdot 2 \mathrm{H}_{2} \mathrm{O}$ at $0 \mathrm{ppm}$.

For hydrogen NMR measurements, the borane samples were 50 loaded under $\mathrm{N}_{2}$ into glass tubes $5 \mathrm{~mm}$ in outer diameter (OD) and $16 \mathrm{~cm}$ long. The tubes were sealed by flame immediately after being taken out. Hydrogen NMR measurements of the static samples (not spinning) at $85.03 \mathrm{MHz}$ were made in a $2.0 \mathrm{~T}$ electromagnet with ${ }^{19} \mathrm{~F}$ NMR stabilization. Temperature control 55 was provided by flowing cold $\mathrm{N}_{2}$ gas after passing through a thermostatically controlled heater. A thermocouple was placed within $2 \mathrm{~cm}$ of the sample. There was no appreciable temperature gradient because of the rapidly flowing gas for both cooling and heating.

60 Line shapes were generated from Fourier transformation of the FIDs. The decays were generated with short radio frequency (RF) pulses, 1 or $2 \mu$ s, to avoid distortion. The FIDs were extrapolated back to time zero using a Gaussian function, to replace the early signals that were corrupted by probe ringing and receiver 65 recovery. ${ }^{17}$ These corrections and precautions are only important for very broad signals (broader than $30 \mathrm{kHz}$ ), as observed here at low temperatures.

The hydrogen spin-lattice relaxation time $\mathrm{T}_{1}$ was measured by the saturate-wait-inspect strategy. ${ }^{18}$ Complete saturation was 70 obtained by a train of twenty $\pi / 2$ RF pulses spaced at 1 ms each. Inspection used the FID following a final $\pi / 2$ pulse (typical duration of $8.5 \mu \mathrm{s}$ ).

\section{Calculation details}

The structure of $\mathrm{NaB}_{3} \mathrm{H}_{8}$ has been solved based on powder $\mathrm{X}$ 75 ray diffraction (XRD) analysis, ${ }^{14}$ which is less sensitive to $\mathrm{H}$ atom positions than either single-crystal XRD or powder neutron diffraction (on deuterated samples). DFT calculations were carried out to optimize the structure with the aim of obtaining better $\mathrm{H}$ positions in the crystal packing. The calculation was 80 executed using CASTEP (Accerlys, Inc; San Diego, California, USA). A norm-conserving non-local pseudopotential generated by the Kerker scheme with an energy cut-off of $400 \mathrm{eV}$ was utilized. An energy change per atom convergence criterion of $0.00002 \mathrm{eV}$, a root-mean-square displacement of $0.001 \AA$, and a 85 root-mean-square residual force on movable atoms of $0.05 \mathrm{eV} / \AA$ were chosen. Electron exchange interactions and correlation were developed by $\mathrm{Wu}$ and Cohen via a generalized gradient approximation. ${ }^{19}$ Starting atomic positions for the geometry optimization were obtained from powder XRD analysis for ${ }_{90} \mathrm{NaB}_{3} \mathrm{H}_{8} \cdot{ }^{14}$ Symmetry was then relaxed to $P 1$, where atoms could move freely during geometry optimization via the BroydenFletcher-Goldfarb-Shanno scheme.

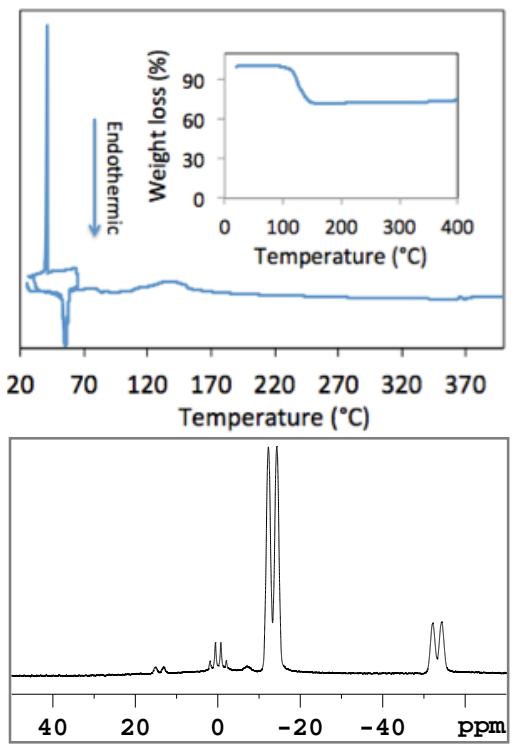

Fig. 1 DSC/TGA curves of unsolvated $\mathrm{NaB}_{3} \mathrm{H}_{8}$ (top) and ${ }^{11} \mathrm{~B}$ 
NMR spectrum of gaseous products dissolved in THF (bottom). $\mathrm{B}_{2} \mathrm{H}_{6}$ (exists as THF. $\left.\mathrm{BH}_{3}, \delta 0 \mathrm{ppm}\right), \mathrm{B}_{6} \mathrm{H}_{10}(\delta 14.2 \mathrm{ppm}$ ) and $\mathrm{B}_{5} \mathrm{H}_{9}(\delta-13.9 \mathrm{ppm}, \delta$-53.8 ppm) were detected.

\section{Results and discussion}

\section{Thermal decomposition}

The DSC scan of $\mathrm{NaB}_{3} \mathrm{H}_{8}$ shows an endothermic peak at $55^{\circ} \mathrm{C}$ upon heating, a sharp exothermic peak at $41{ }^{\circ} \mathrm{C}$ during a subsequent cooling at the same rate, and reappearance of the endothermic peak at the same temperature (Fig. 1 (top)). This 10 indicates a phase change in $\mathrm{NaB}_{3} \mathrm{H}_{8}$ upon heating. XRD analysis carried out under inert atmosphere (due to the hygroscopic nature of the compound) at various temperatures combined with DFT calculations might help elucidate the details of this change in the crystal structure. Combined DSC and TGA results show 15 decomposition starting from $100{ }^{\circ} \mathrm{C}$, resulting in a weight loss of $\sim 30$ wt \% (Fig. 1 (top)). NMR analysis reveals that $\mathrm{B}_{2} \mathrm{H}_{6}$, hexaborane $\left(\mathrm{B}_{6} \mathrm{H}_{10}\right)$, and $\mathrm{B}_{5} \mathrm{H}_{9}$ coexist in the gaseous products (Fig. 1 (bottom) $)^{20}$, with the majority of the content being $\mathrm{B}_{5} \mathrm{H}_{9}$ (Table 1). This is consistent with earlier results. ${ }^{21}$

20 A similar phase change at $70{ }^{\circ} \mathrm{C}$ is observed when $\mathrm{NH}_{3} \mathrm{~B}_{3} \mathrm{H}_{7}$ was subjected to a DSC scan. Thermal decomposition is exothermic, starting from $100{ }^{\circ} \mathrm{C}$, with a final weight loss of over 70 wt \% (Fig. 2 (top)). NMR analysis indicates that not only $\mathrm{B}_{2} \mathrm{H}_{6}, \mathrm{~B}_{6} \mathrm{H}_{10}$, and $\mathrm{B}_{5} \mathrm{H}_{9}$, but also borazine $\left(\mathrm{B}_{3} \mathrm{~N}_{3} \mathrm{H}_{6}\right)$ and 25 aminodiborane $\left(\mathrm{B}_{2} \mathrm{NH}_{7}\right)^{20}$ are present in the gaseous decomposition products (Fig. 2 (bottom)). Based on the NMR signal integration ratio, similar amounts of $\mathrm{B}_{2} \mathrm{H}_{6}$ and $\mathrm{B}_{5} \mathrm{H}_{9}$ were released (Table 1 ). The presence of these volatile species leads to the large weight loss, considering that there is only $17.7 \mathrm{wt} \% \mathrm{H}$ 30 in this compound.
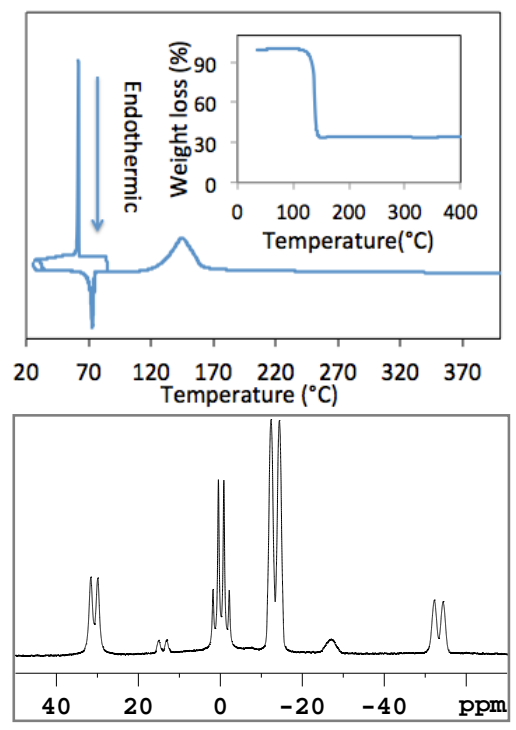

Fig. 2 DSC/TGA curves of $\mathrm{NH}_{3} \mathrm{~B}_{3} \mathrm{H}_{7}$ (top) and ${ }^{11} \mathrm{~B}$ NMR spectrum of gaseous products dissolved in THF (bottom). $\mathrm{B}_{2} \mathrm{H}_{6}$ (exists as THF. $\left.\mathrm{BH}_{3}, \delta 0 \mathrm{ppm}\right), \mathrm{B}_{5} \mathrm{H}_{9}(\delta-13.9 \mathrm{ppm},-53.8 \mathrm{ppm})$, ${ }_{35} \mathrm{~B}_{6} \mathrm{H}_{10}(\delta 14.2 \mathrm{ppm}), \mathrm{B}_{3} \mathrm{~N}_{3} \mathrm{H}_{6}(\delta 30.8 \mathrm{ppm})$, and $\mathrm{B}_{2} \mathrm{NH}_{7}(\delta-27.5$ ppm) were detected.
Previous DSC and TGA results on $\mathrm{NH}_{4} \mathrm{~B}_{3} \mathrm{H}_{8}$ indicated that melting and decomposition take place simultaneously at $120^{\circ} \mathrm{C}$, 40 leading to $~ 70$ wt \% weight loss. ${ }^{15}$ Similar to $\mathrm{NH}_{3} \mathrm{~B}_{3} \mathrm{H}_{7}$, appreciable amounts of $\mathrm{B}_{2} \mathrm{H}_{6}, \mathrm{~B}_{5} \mathrm{H}_{9}, \mathrm{~B}_{3} \mathrm{~N}_{3} \mathrm{H}_{6}$, and $\mathrm{B}_{2} \mathrm{NH}_{7}$ were identified in the decomposition products by NMR analysis (Fig. 3). Mass spectroscopy did not detect $\mathrm{NH}_{3}$ in the gaseous product.

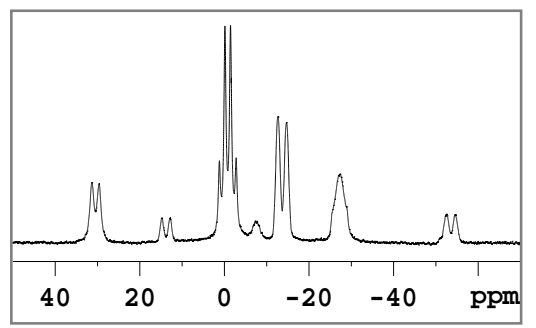

${ }_{45}$ Fig. $3{ }^{11} \mathrm{~B}$ NMR spectrum of gaseous products from $\mathrm{NH}_{4} \mathrm{~B}_{3} \mathrm{H}_{8}$ dissolved in THF. $\mathrm{B}_{2} \mathrm{H}_{6}$ (exists as THF. $\left.\mathrm{BH}_{3}, \delta 0 \mathrm{ppm}\right), \mathrm{B}_{5} \mathrm{H}_{9}(\delta-$ 13.9 ppm, -53.8 ppm), $\mathrm{B}_{6} \mathrm{H}_{10}$ ( $\left.\delta 14.2 \mathrm{ppm}\right), \mathrm{B}_{3} \mathrm{~N}_{3} \mathrm{H}_{6}$ ( $\left.\delta 30.8 \mathrm{ppm}\right)$, and $\mathrm{B}_{2} \mathrm{NH}_{7}(\delta-27.5 \mathrm{ppm})$ were detected.

50 During the thermal decomposition of these compounds four common gaseous products were observed: $\mathrm{H}_{2}, \mathrm{~B}_{2} \mathrm{H}_{6}, \mathrm{~B}_{6} \mathrm{H}_{10}$, and $\mathrm{B}_{5} \mathrm{H}_{9} . \mathrm{B}_{3} \mathrm{~N}_{3} \mathrm{H}_{6}$ and $\mathrm{B}_{2} \mathrm{NH}_{7}$ were observed in the case of $\mathrm{NH}_{4} \mathrm{~B}_{3} \mathrm{H}_{8}$ and $\mathrm{NH}_{3} \mathrm{~B}_{3} \mathrm{H}_{7}$. These results indicate that upon heating, the boron triangle ruptures and gives off $\mathrm{H}_{2}, \mathrm{~B}_{2} \mathrm{H}_{6}, \mathrm{~B}_{6} \mathrm{H}_{10}$, and $\mathrm{B}_{5} \mathrm{H}_{9}$. The 55 volatile borane species then react with $\mathrm{NH}_{4}^{+}$(in the case of $\mathrm{NH}_{4} \mathrm{~B}_{3} \mathrm{H}_{8}$ ) and $\mathrm{NH}_{3}$ (in the case of $\mathrm{NH}_{3} \mathrm{~B}_{3} \mathrm{H}_{7}$ ), forming $\mathrm{B}_{3} \mathrm{~N}_{3} \mathrm{H}_{6}$ and $\mathrm{B}_{2} \mathrm{NH}_{7}$.

Table 1. Relative amounts of boron species observed in the 60 decomposition products. $\left(\mathrm{B}_{5} \mathrm{H}_{9}, \mathrm{~B}_{3} \mathrm{~N}_{3} \mathrm{H}_{6}\right.$, and $\mathrm{B}_{2} \mathrm{NH}_{7}$ are referenced to $\mathrm{B}_{2} \mathrm{H}_{6}$, which was set to 1.)

\begin{tabular}{|c|c|c|c|c|c|}
\hline Compound & $\mathrm{B}_{2} \mathrm{H}_{6}$ & $\mathrm{~B}_{6} \mathrm{H}_{10}$ & $\mathrm{~B}_{5} \mathrm{H}_{9}$ & $\mathrm{~B}_{3} \mathrm{~N}_{3} \mathrm{H}_{6}$ & $\mathrm{~B}_{2} \mathrm{NH}_{7}$ \\
\hline $\mathrm{NaB}_{3} \mathrm{H}_{8}$ & 1 & 0.19 & 3 & n/a & n/a \\
\hline $\mathrm{NH}_{4} \mathrm{~B}_{3} \mathrm{H}_{8}$ & 1 & 0.05 & 0.37 & 0.24 & 0.49 \\
\hline $\mathrm{NH}_{3} \mathrm{~B}_{3} \mathrm{H}_{7}$ & 1 & 0.04 & 0.9 & 0.4 & 0.2 \\
\hline
\end{tabular}

Our preliminary results have shown that adding porous ${ }_{65}$ frameworks such as silica and transition metals such as Co suppresses the formation of volatile boranes, but not completely. These compounds are unlikely to be candidates for hydrogen storage through thermolysis.

\section{NMR studies}

70 The solid residue has been characterized using the MAS NMR technique. The ${ }^{11} \mathrm{~B}$ NMR spectrum of the solid decomposition products of $\mathrm{NaB}_{3} \mathrm{H}_{8}$ (Fig. 4) shows a strong peak at $-40.6 \mathrm{ppm}$ that is due to $\mathrm{BH}_{4}^{-}$and a weak peak at $-14.0 \mathrm{ppm}$ associated with $\mathrm{B}_{12} \mathrm{H}_{12}{ }^{2-}{ }^{22}$ The little broad peak at $1.9 \mathrm{ppm}$ is ascribed to $75 \mathrm{~B}(\mathrm{OH})_{4}{ }^{-23}$ which is formed via reaction with water and oxygen during sample storage and/or thermal decomposition. This finding is consistent with earlier reports that $\mathrm{BH}_{4}{ }^{-}$and $\mathrm{B}_{12} \mathrm{H}_{12}{ }^{2-}$ form upon the decomposition of $\mathrm{B}_{3} \mathrm{H}_{8}{ }^{-}$salts. ${ }^{21}$

In the cases of $\mathrm{NH}_{3} \mathrm{~B}_{3} \mathrm{H}_{7}$ and $\mathrm{NH}_{4} \mathrm{~B}_{3} \mathrm{H}_{8}$, a sharp peak at 1.6 $80 \mathrm{ppm}$ associated with $\mathrm{B}(\mathrm{OH})_{4}{ }^{-}$is identified. ${ }^{11} \mathrm{~B}$ NMR spectra are included in the Supplementary Information. The broad peak 
extending from +30 to $-20 \mathrm{ppm}$ is indicative of the formation of amorphous elemental boron. ${ }^{22} \mathrm{~B}_{12} \mathrm{H}_{12}{ }^{2-}(\delta-14.0 \mathrm{ppm})$ is identified in the solid decomposition products of $\mathrm{NH}_{4} \mathrm{~B}_{3} \mathrm{H}_{8}$, but not in those of $\mathrm{NH}_{3} \mathrm{~B}_{3} \mathrm{H}_{7}$. This is likely caused by the differences between ${ }_{5} \mathrm{NH}_{4} \mathrm{~B}_{3} \mathrm{H}_{8}$ and $\mathrm{NH}_{3} \mathrm{~B}_{3} \mathrm{H}_{7}$, such as the ionic interactions between $\mathrm{NH}_{4}{ }^{+}$and $\mathrm{B}_{3} \mathrm{H}_{8}{ }^{-}$in comparison with the covalent bonds between $\mathrm{NH}_{3}$ and $\mathrm{B}_{3} \mathrm{H}_{7}$, and the weak dihydrogen interactions in $\mathrm{NH}_{4} \mathrm{~B}_{3} \mathrm{H}_{8}$ in contrast to the strong ones in $\mathrm{NH}_{3} \mathrm{~B}_{3} \mathrm{H}_{7}$. ${ }^{10}$

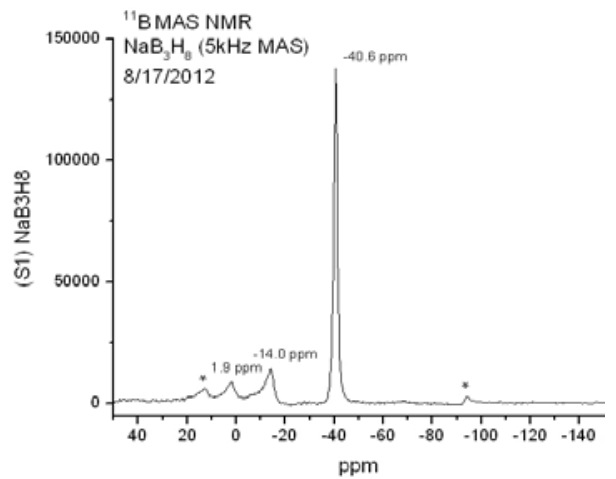

Fig. $4{ }^{11} \mathrm{~B}$ NMR spectrum of the solid decomposition products of $\mathrm{NaB}_{3} \mathrm{H}_{8}$. The main peaks are identified as $\mathrm{BH}_{4}{ }^{-}(\delta-40.6 \mathrm{ppm})$, $\mathrm{B}_{12} \mathrm{H}_{12}{ }^{2-}(\delta-14.0 \mathrm{ppm})$, and $\mathrm{B}(\mathrm{OH})_{4}{ }^{-}$(1.9 ppm). The most distant little peaks (marked with $*$ ) are spinning sidebands.

15

${ }^{1} \mathrm{H}$ NMR spectra of $\mathrm{NH}_{3} \mathrm{~B}_{3} \mathrm{H}_{7}$ at several representative temperatures are presented in Fig. 5. ${ }^{1} \mathrm{H}$ NMR spectra of $\mathrm{NH}_{4} \mathrm{~B}_{3} \mathrm{H}_{8}$ and $\mathrm{NaB}_{3} \mathrm{H}_{8}$ are provided in the Supporting Information. Each solid undergoes motional narrowing ${ }^{24,25,26}$ 20 from $-135{ }^{\circ} \mathrm{C}$ (or $-125^{\circ} \mathrm{C}$ ) to $21^{\circ} \mathrm{C}$. For each sample, a narrow resonance "pip” appears at and above $21^{\circ} \mathrm{C}$, off-scale; this signal contains a small fraction of the total spectral area and the total ${ }^{1} \mathrm{H}$ spins. These impurity signals have been attributed to residual solvent from the sample preparation.

25

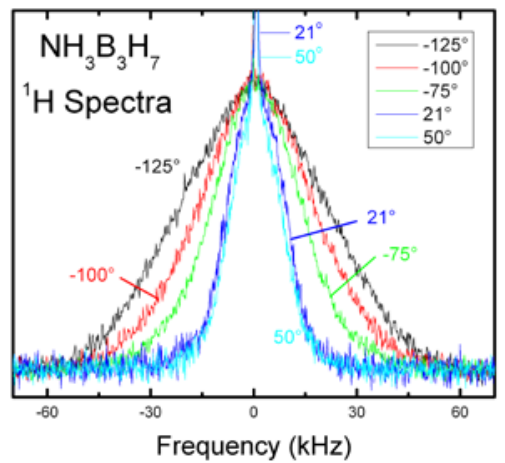

Fig. 5 Hydrogen NMR spectra of $\mathrm{NH}_{3} \mathrm{~B}_{3} \mathrm{H}_{7}$ at several temperatures (listed in ${ }^{\circ} \mathrm{C}$ ).

30 Full width at half of maximum (FWHM) line widths were obtained from the experimental spectra and are presented in Fig. 6. None of the solids is at its rigid lattice limit at -135 or $-125^{\circ} \mathrm{C}$, but by comparison with organic solids (e.g., cyclohexane) ${ }^{24}$ with similar densities of ${ }^{1} \mathrm{H}$ spins, the expected rigid $\mathrm{FWHM}$ is 35 approximately $60 \mathrm{kHz}$. $\mathrm{NaB}_{3} \mathrm{H}_{8}$ and $\mathrm{NH}_{3} \mathrm{~B}_{3} \mathrm{H}_{7}$ must commence narrowing just below $-135{ }^{\circ} \mathrm{C}$, while $\mathrm{NH}_{4} \mathrm{~B}_{3} \mathrm{H}_{8}$ (the narrowest resonance of the three at $-135^{\circ} \mathrm{C}$ ) must begin narrowing well below this temperature. Thus, since $\mathrm{NH}_{4} \mathrm{~B}_{3} \mathrm{H}_{8}$ exhibits reorientation starting from the lowest temperature, one expects 40 the reorientations in $\mathrm{NH}_{4} \mathrm{~B}_{3} \mathrm{H}_{8}$ to have the smallest activation energy.

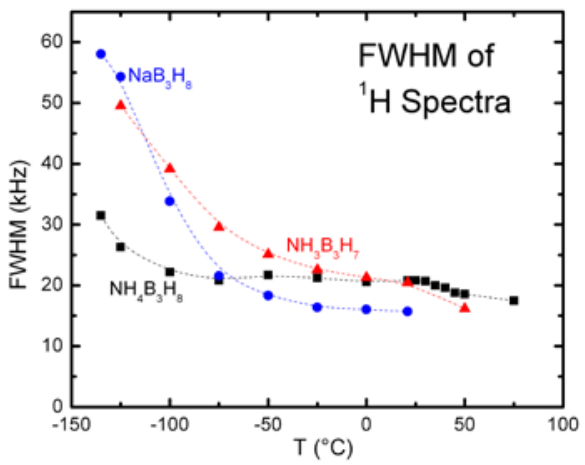

Fig. 6 Hydrogen NMR FWHM line widths as functions of 45 temperature T. Dashed lines are guides for the eyes and carry no analytical significance. All line widths carry a $\pm 5 \%$ uncertainty.

In the plateau region near $21^{\circ} \mathrm{C}$ (see Fig. 6), the line shapes are approximately Gaussian. The second moment $\mathrm{M}_{2}$ (in units of 50 (radians $/ \mathrm{s})^{2}$ ) and the FWHM line width (in $\mathrm{Hz}$ units) are related by $^{26}$

$$
\mathrm{FWHM}=\left(2 \ln 2 \mathrm{M}_{2}\right)^{1 / 2} / \pi
$$

An important theorem holds that one can calculate the $\mathrm{M}_{2}$, when the molecular units reorient rapidly, isotropically, and 55 independently, by placing all of the spins in a reorienting molecule or sub-unit at the molecular center. ${ }^{24}$ For like-spin interactions, the powder-average $\mathrm{M}_{2}$ is given by ${ }^{26}$

$$
M_{2}=3 / 5 \gamma_{I}^{4} \hbar^{2} I(I+1) \sum_{k} 1 / r_{k}^{6}
$$

where the lattice sum $S$ is well-approximated by $^{24}$

60

$$
S=n 7.25 / V^{2}
$$

Here $\gamma_{1}$ is the magnetogyric ratio of the hydrogen nuclear spin, $I$ $=1 / 2$ for hydrogen, $n$ is the number of ${ }^{1} \mathrm{H}$ spins on each molecular unit, and $V$ is the volume per molecular unit. Provided that the structure is densely packed, the numerical factor in (3) is nearly 65 constant and almost independent of structural details. For all three solids, we have verified that unlike-spin (boron, sodium) contributions to the hydrogen M2 are small, less than $10 \%$ (so a < 5\% contribution to the FWHM line width).

For $\mathrm{NH}_{3} \mathrm{~B}_{3} \mathrm{H}_{7}$, the reported crystal structure has $\mathrm{V}=112.2$ $70 \AA^{3} /$ molecule. ${ }^{10}$ The entire molecule was modelled with $n=10{ }^{1} \mathrm{H}$ spins rotating isotropically, yielding $\mathrm{M}_{2}=1.47 \times 10^{9}(\mathrm{rad} / \mathrm{s})^{2}$ and FWHM $=14.4 \mathrm{kHz}$. In this case, the observed FWHM of 20.5 $\mathrm{kHz}$ is sufficiently larger than the calculated value that we suspect the reorientations are not fully isotropic.

75 For $\mathrm{NaB}_{3} \mathrm{H}_{8}$, the crystal structure ${ }^{14}$ is reported with $V=109.2$ $\AA^{3} /$ molecule and $n=8{ }^{1} \mathrm{H}$ spins. Letting each $\mathrm{B}_{3} \mathrm{H}_{8}$ group rotate isotropically gives $\mathrm{M}_{2}=1.24 \times 10^{9}(\mathrm{rad} / \mathrm{s})^{2}$ and $\mathrm{FWHM}=13.2$ $\mathrm{kHz}$. This is close to the observed $15.5 \mathrm{kHz}$ FWHM at $21{ }^{\circ} \mathrm{C}$, indicating nearly isotropic reorientation at this temperature.

80 The case of $\mathrm{NH}_{4} \mathrm{~B}_{3} \mathrm{H}_{8}$ is more complicated, as there are $4{ }^{1} \mathrm{H}$ spins on $\mathrm{NH}_{4}^{+}$and 8 on $\mathrm{B}_{3} \mathrm{H}_{8}{ }^{-}$; cations and anions are modelled to reorient independently of each other. Using $124 \AA^{3}$ per $\mathrm{NH}_{4} \mathrm{~B}_{3} \mathrm{H}_{8}$ formula unit from the structure determined from $\mathrm{XRD},{ }^{15} \mathrm{M}_{2}=3.17 \times 10^{9}(\mathrm{rad} / \mathrm{s})^{2}$ and $\mathrm{FWHM}=21.1 \mathrm{kHz}$ agrees 85 with the observed $21 \mathrm{kHz}$ FWHM.

Overall, the agreement between the measured FWHM line 
widths and the calculated values demonstrates that isotropic reorientations occur at $2{ }^{\circ} \mathrm{C}$ (or, in the case of $\mathrm{NH}_{3} \mathrm{~B}_{3} \mathrm{H}_{7}$, nearly isotropic reorientations).

Above $21{ }^{\circ} \mathrm{C}$, the $\mathrm{NH}_{3} \mathrm{~B}_{3} \mathrm{H}_{7}$ and $\mathrm{NH}_{4} \mathrm{~B}_{3} \mathrm{H}_{8}$ line widths narrow 5 further; the $\mathrm{NaB}_{3} \mathrm{H}_{8}$ material was judged to be insufficiently stable for study at elevated temperatures. The additional narrowing may signal the onset of translational self-diffusion, although the slope of the observed decrease is too small for the expected, thermally activated behavior. ${ }^{24}$ In any event, the lines 10 remain broader than $10 \mathrm{kHz}$ at and below $75^{\circ} \mathrm{C}$, so the diffusion motion is never rapid on the $10^{-5} \mathrm{~s}$ NMR time scale at this temperature.

The spin-lattice relaxation time $T_{1}$ is reported in Fig. 7. The $T_{1}$ of all three solids passes through a deep minimum near or just 15 below room temperature. First, we examine the temperature of the $\mathrm{T}_{1}$ minimum. A minimum is expected in standard relaxation theory ${ }^{24,25,26}$ when $\omega_{0} \tau$, with $\omega_{0}$ the attempt frequency, is approximately one, so $\tau$ (the motion correlation time) is about $10^{-}$ ${ }^{9} \mathrm{~s}$; here $\omega_{\mathrm{o}}$ is $2 \pi$ times the resonance frequency of $85.03 \mathrm{MHz}$. 20 The onset of line narrowing occurs for $\tau$ of approximately $10^{-5} \mathrm{~s}$ (the reciprocal of the rigid limit line width). Motions (reorientations) here are assumed to be described by the thermal activation expression, $1 / \tau=\omega_{0} \exp (-\mathrm{E} / \mathrm{kT})$, with a typical attempt frequency of $\omega_{0}=10^{13} \mathrm{~s}^{-1}$. At the $T_{1}$ minimum, the factor exp(${ }_{25} \mathrm{E} / \mathrm{kT}$ ) is $10^{-4}$, while at the onset of line narrowing this factor is $10^{-}$ ${ }^{8}$. Thus, the absolute temperature at the $T_{1}$ minimum should be approximately double that at the onset of narrowing.

For $\mathrm{NH}_{3} \mathrm{~B}_{3} \mathrm{H}_{7}$, the $\mathrm{T}_{1}$ minimum occurs near $21{ }^{\circ} \mathrm{C}$, predicting the narrowing onset to be near $-126{ }^{\circ} \mathrm{C}$, slightly higher than our 30 estimate above based on the line widths. For $\mathrm{NaB}_{3} \mathrm{H}_{8}$, the $\mathrm{T}_{1}$ minimum appears at $-23{ }^{\circ} \mathrm{C}$. The onset of narrowing is thus predicted to be $-148{ }^{\circ} \mathrm{C}$, which agrees well with the line width analysis. For $\mathrm{NH}_{4} \mathrm{~B}_{3} \mathrm{H}_{8}$, the $\mathrm{T}_{1}$ minimum occurs at $-51^{\circ} \mathrm{C}$, leading to a predicted temperature of $-162{ }^{\circ} \mathrm{C}$ for the onset of narrowing. 35 Again, this prediction agrees with the line width values. For comparison, in $\mathrm{NH}_{4} \mathrm{Cl}$, the $\mathrm{T} 1$ minimum occurs near $-78{ }^{\circ} \mathrm{C}^{27}$ and the onset of narrowing near $-158{ }^{\circ} \mathrm{C}^{28}$, in the same vicinity as the temperatures reported here for $\mathrm{NH}_{4} \mathrm{~B}_{3} \mathrm{H}_{8}$. The $\mathrm{T}_{1}$ minimum in this sample is particularly broad, suggesting that the reorientation 40 rates of the $\mathrm{NH}_{4}{ }^{+}$cations and the $\mathrm{B}_{3} \mathrm{H}_{8}{ }^{-}$anions are somewhat different, but not sufficiently different to yield a resolved double minimum in $T_{1}$. Overall, the observed relationship between the temperatures of the $T_{1}$ minima and the narrowing onsets demonstrates that the same thermally activated process (i.e., 45 molecular reorientation) controls both.

Next, we examine the depth of the $T_{1}$ minima. All of these solids have approximately the same densities of ${ }^{1} \mathrm{H}$ spins, so their low-temperature limiting (rigid limit) $\mathrm{M}_{2}$ values and FWHM rigid line widths should be approximately equal. ${ }^{24}$ The FWHM was set 50 to $60 \mathrm{kHz}$, and the portion of $\mathrm{M}_{2}$ (about 89\%) that is motionally modulated, $\Delta \mathrm{M}_{2}=2.3 \times 10^{10}(\mathrm{rad} / \mathrm{s})^{2}$, was computed using equation (1). The minimum $T_{1}$ is given by (with a very small model dependence): ${ }^{24}$

$$
\mathrm{T}_{1} \min =(1.0) \omega_{0} / \Delta \mathrm{M}_{2}=0.023 \mathrm{~s}
$$

55 The above estimate is rough, but it applies to all three solids. The agreement in Fig. 7 (see dashed line) with $\mathrm{NaB}_{3} \mathrm{H}_{8}$ is quite good. The minimum $\mathrm{T}_{1}$ for $\mathrm{NH}_{4} \mathrm{~B}_{3} \mathrm{H}_{8}$ is slightly larger, quite likely due to the extra breadth of the minimum in this solid, due to the separate reorientation rates for the cations and anions. For ${ }_{60} \mathrm{NH}_{3} \mathrm{~B}_{3} \mathrm{H}_{7}$, the dashed curves (only guides to the eye) in Fig. 7 show a discontinuity in slope near the reported solid-solid phase transition at $24{ }^{\circ} \mathrm{C} .{ }^{29}$ For this sample, the $\mathrm{T}_{1}$ minimum appears to be pre-empted by the transition, so the true minimum value of $T_{1}$ is never obtained.

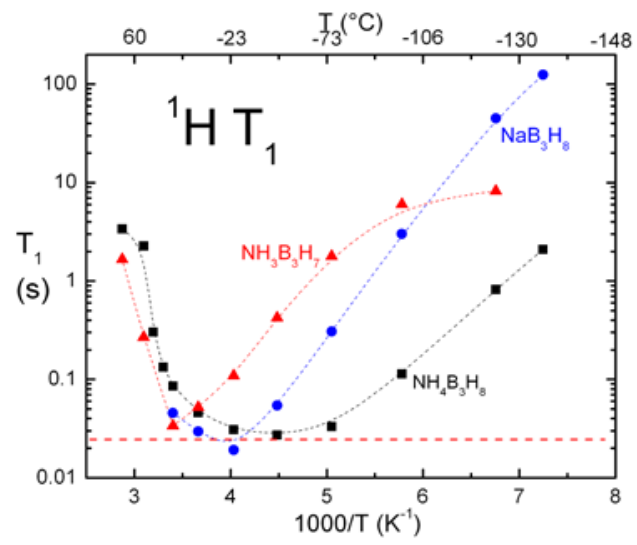

Fig. 7 Hydrogen spin-lattice relaxation time $T_{1}$ dependence on inverse temperature for the three solids. The dashed curves are guides for the eyes. The $T_{1}$ values have a $\pm 10 \%$ uncertainty. The dashed horizontal line is the theoretical estimate for the minimum $70 \mathrm{~T}_{1}$.

Overall, the good agreement of the predicted and measured minimum $\mathrm{T}_{1}$ values confirms that the same motions (molecular reorientations) control $\mathrm{T}_{1}$ and the line narrowing.

75 The activation energy of molecular reorientations was calculated using $\tau=10^{-9} \mathrm{~s}$ at the $\mathrm{T}_{1}$ minimum and an assumed attempt rate $\omega_{0}=10^{13} \mathrm{~s}^{-1}$. Thus, at the $T_{1}$ minimum, $\exp (-\mathrm{E} / \mathrm{kT})$ is approximately $10^{-4}$. So, the activation energy $\mathrm{E}$ in $\mathrm{NH}_{3} \mathrm{~B}_{3} \mathrm{H}_{7}$, $\mathrm{NaB}_{3} \mathrm{H}_{8}$, and $\mathrm{NH}_{4} \mathrm{~B}_{3} \mathrm{H}_{8}$ is $0.23,0.20$, and $0.18 \mathrm{eV}$, respectively. 80 While we can trust the relative values of $\mathrm{E}$ to $\pm 10 \%$, the absolute values depend on the assumed attempt frequency $\omega_{0}$ and are likely to be reliable only to $\pm 25 \%$ (reflecting a \pm 1 decade uncertainty in $\omega_{0}$ ).

\section{${ }_{85}$ DFT geometry optimization}

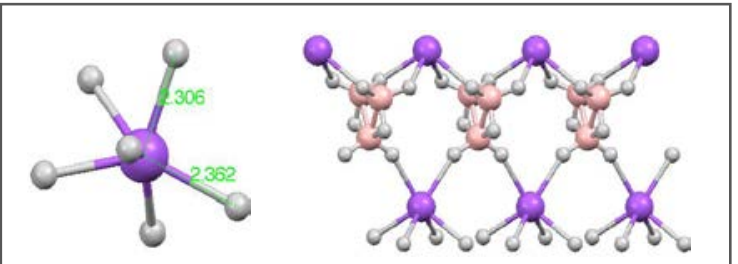

Fig. 8 DFT optimized crystal structure of $\mathrm{NaB}_{3} \mathrm{H}_{8}$. Left: $\mathrm{Na}^{+}$ coordinated by six $\mathrm{H}^{+}$; right: double stranded structure constraining the movement of $\mathrm{B}_{3} \mathrm{H}_{8}{ }^{-}$. Purple: Na; Grey: H; Pink: B.

90

Geometry optimization by DFT indicates that there is no major change in the original structure, but movement of terminal hydrogen on the boron triangle towards the $\mathrm{Na}^{+}$cation indicates a strong $\mathrm{Na}---\mathrm{H}$ interaction (Fig. 8). Each $\mathrm{Na}^{+}$is coordinated by 6 ${ }_{95} \mathrm{H}^{+}$in a distorted octahedron, with the $\mathrm{Na} \cdots \mathrm{H}$ distance $\sim 2.3 \AA$, 
shorter than those in $\mathrm{NaBH}_{4}(2.44 \AA-2.59 \AA) .{ }^{30}$ With all terminal hydrogen atoms on the boron triangle interacting with $\mathrm{Na}^{+}$, the movement of $\mathrm{B}_{3} \mathrm{H}_{8}$ units will likely be constrained, which results in a high activation energy for reorientation of $\mathrm{B}_{3} \mathrm{H}_{8}{ }^{-}$.

5 The crystal structures of $\mathrm{NH}_{4} \mathrm{~B}_{3} \mathrm{H}_{8}$ and $\mathrm{NH}_{3} \mathrm{~B}_{3} \mathrm{H}_{7}$ have been solved based on single crystal XRD analysis, which affords much better resolution of atomic locations. Separate ion pairs exist in the $\mathrm{NH}_{4} \mathrm{~B}_{3} \mathrm{H}_{8}$ crystal structure, where $\mathrm{N}-\mathrm{H}^{+\cdots} \mathrm{H}^{-}-\mathrm{B}$ dihydrogen interaction is weak. ${ }^{15}$ This leads to easy reorientation of $\mathrm{NH}_{4}{ }^{+}$and ${ }_{10} \mathrm{~B}_{3} \mathrm{H}_{8}{ }^{-}$. In $\mathrm{NH}_{3} \mathrm{~B}_{3} \mathrm{H}_{7}$, the $\mathrm{N}$ atom forms a strong bond with one of the $\mathrm{B}$ atoms. Additionally, extensive $\mathrm{N}-\mathrm{H}^{+} \ldots \mathrm{H}^{-}-\mathrm{B}$ networks exist in the crystal structure. ${ }^{10}$ As a result, the reorientation of the molecule is much constrained. Overall, structural features of the three compounds shed light on the ease of molecular 15 reorientation.

\section{Conclusions}

The thermal decomposition of $\mathrm{NaB}_{3} \mathrm{H}_{8}, \mathrm{NH}_{4} \mathrm{~B}_{3} \mathrm{H}_{8}$, and $\mathrm{NH}_{3} \mathrm{~B}_{3} \mathrm{H}_{7}$ has been investigated. Hydrogen, diborane, pentaborane, and hexaborane are the common decomposition 20 products; the presence of $\mathrm{NH}_{3}$ and $\mathrm{NH}_{4}{ }^{+}$constituents causes the additional formation of borazine and aminodiborane. These compounds are unlikely candidates for hydrogen storage via thermolysis due to these volatile side products. Static solid-state ${ }^{1} \mathrm{H}$ NMR was used to determine the nature of the molecular 25 motions. In all three, line narrowing is observed from $-135{ }^{\circ} \mathrm{C}$ to $21{ }^{\circ} \mathrm{C}$ and is attributed to reorientations of the molecular subunits. Translational self-diffusion, which is an important aspect of rapid hydrogen reactions in the solid state, is never rapid on the NMR time scale of $10^{-5} \mathrm{~s}$. The hydrogen spin-lattice relaxation 30 time $T_{1}$ passes through a minimum for each of the solids. The temperature and depth of the $\mathrm{T}_{1}$ minima are in accordance with molecular reorientations being the source of the relaxation.

\section{Acknowledgement}

The work at The Ohio State University is funded by the U.S. 35 Department of Energy, Office of Energy Efficiency and Renewable Energy (EERE) under Contract No. DEFC3605GO15062. M. S. C. at Washington University gratefully acknowledges support from the U.S. Department of Energy, Basic Energy Sciences, from grant DE-FG02-05ER46256. Z. H. 40 is a recipient of an Australian Research Council's Discovery Early Career Researcher Award (project number DE120101496). Z. H. thanks Professor L. G. Sneddon for his comments on ${ }^{11} \mathrm{~B}$ NMR analysis. We thank S.-J. Hwang for suggestions on the spectral assignment of the ${ }^{11} \mathrm{~B}$ MAS-NMR.

\section{${ }_{45}$ Notes and references}

${ }^{a}$ Department of Materials Science and Engineering, The Ohio State University, Columbus, OH, 43210, USA. Fax:1 614292 1537; Tel: 1614 292 9462. E-mail: zhao.199@osu.edu.

${ }^{b}$ Institute for Superconducting and Electronic Materials, University of 50 Wollongong, Wollongong, New South Wales 2522, Australia. Fax:61 2 4221 5731; Tel:61 24221 3220. E-mail: zhenguo@uow.edu.au.

${ }^{c}$ Department of Physics, Washington University, CB-1105, 1 Brookings Drive, St. Louis, Missouri 63130. Fax: 1314935 6219; Tel: 1314935 6292.E-mail: msc@wuphys.wustl.edu.

${ }_{55}{ }^{d}$ Department of Physics, South Dakota School of Mines and Technology, 501 East Saint Joseph Street, Rapid City, SD 57701, USA.
† Electronic Supplementary Information (ESI) available: Hydrogen NMR spectra of $\mathrm{NH}_{4} \mathrm{~B}_{3} \mathrm{H}_{8}$ and $\mathrm{NaB}_{3} \mathrm{H}_{8}$ at several temperatures (listed in ${ }^{\circ} \mathrm{C}$ ). ${ }^{11} \mathrm{~B}$ 60 NMR spectra of the solid decomposition products of $\mathrm{NH}_{3} \mathrm{~B}_{3} \mathrm{H}_{7}$ and $\mathrm{NH}_{4} \mathrm{~B}_{3} \mathrm{H}_{8}$. See DOI: $10.1039 / \mathrm{b} 000000 \mathrm{x} /$

1 J. Baumann, F. Baitalow and F. P. Hoffmann, Thermochim. Acta, 2000, 343, 19; F. Baitalow, J. Baumann, G. Wolf, K. JaenickeRossler and G. Leitner, Thermochim. Acta, 2002, 391, 159.

2 F. H. Stephens, V. Pons and R. T. Baker, Dalton Trans., 2007, 2613; W. J. Shaw, J. C. Linehan, N. K. Szymczak, D. J. Heldebrant, C. Yonker, D. M. Camaioni, R. T. Baker and T. Autrey, Angew. Chem., Int. Ed., 2008, 47, 7493; P. Wang and X. D. Kang, Dalton Trans., 2008, 5400 .

3 Z. Xiong, C. K. Yong, G. Wu, P. Chen, W. Shaw, A. Karkamkar, T. Autrey, M. O. Jones, S. R. Johnson, P. P. Edwards and W. I. F. David, Nat. Mater., 2008, 7, 138; H. V. K. Diyabalanage, R. P. Shrestha, T. A. Semelsberger, B. L. Scott, M. E. Bowden, B. L. Davis and A. K. Burrell, Angew. Chem., Int. Ed., 2007, 46, 8995; A. D. Sutton, A. K. Burrell, D. A. Dixon, E. B. Garner III, J. C. Gordon, T. Nakagawa, K. C. Ott, J. P. Robinson and M. Vasiliu, Science, 2011, 331, 1426.

4 U.S. Department of Energy Hydrogen Program, http://www.hydrogen.energy.gov/annual_review12_proceedings.html , May, 2012.

5 P. Martelli, R. Caputo, A. Remhof, P. Mauron, A. Borgschulte and A. Züttel, J. Phys. Chem. C 2010, 114, 7173; J. Urgnani, F. Torres, M. Palumbo and M. Baricco, Int. J. Hydrogen Energy, 2008, 33, 3111.

6 U.S. Department of Energy Hydrogen Program, "Go/No-Go Recommendation for Sodium Borohydride for On-Board Vehicular Hydrogen Storage”, November, 2007.

7 P. Ngene, M. van Zwienen and P. E. de Jongh, Chem. Commun., 2010, 46, 8201.

8 G. Severa, E. Rönnebrow and C. M. Jensen, Chem. Commun., 2010, 46, 421;

9 J. -C. Zhao, D. A. Knight, G. M. Brown, C. Kim, S. -J. Hwang, J. W. Reiter, R. C. Bowman Jr., J. A. Zan and J. G. Kulleck, J. Phys. Chem. C., 2009, 113, 2; X. Chen, Y. Zhang, Y. Wang, W. Zhou, D. A. Knight, T. B. Yisgedu, Z. Huang, H. K. Lingam, B. Billet, T. J. Udovic, G. M. Brown, S. Shore, C. M. Wolverton and J.-C. Zhao, Chem. Sci., 2012, DOI: 10.1039/c2sc21100a.

10 C. W. Yoon, P. J. Carroll and L. G. Sneddon, J. Am. Chem. Soc., 2009, 131, 855; C. W. Yoon and L. G. Sneddon, J. Am. Chem. Soc., 2006, 128, 13992.

11 D. J. Heldebrant, A. Karkamkar, N. J. Hess, M. Bowden, S. Rassat, F. Zheng, K. Rappe and T. Autrey, Chem. Mater., 2008, 20, 5332.

12 W. V. Hough, L. J. Edwards and A. D. McElroy, J. Am. Chem. Soc., 1956, 78, 689; D. M. Goedde, G. K. Windler and G. S. Girolami, Inorg. Chem., 2007, 46, 2814.

13 M. Chong, A. Karkamkar, T. Autrey, S.-I. Orimo, S. Jalisatgi and C. M. Jensen, Chem. Commun., 2011, 47, 1330.

14 Z. Huang, G. King, X. Chen, J. Hoy, T. Yisgedu, H. K. Lingam, S. G. Shore, P. M. Woodward and J. -C. Zhao, Inorg. Chem., 2010, 49, 8185.

15 Z. Huang, X. Chen, T. Yisgedu, E. A. Meyers, S. G. Shore and J. -C. Zhao, Inorg. Chem., 2011, 50, 3738.

16 Z. Huang, X. Chen, T. Yisgedua, J. -C. Zhao and S. G. Shore, Int. J. Hydrogen Energy, 2011, 36, 7038.

17 S. K. Brady, M. S. Conradi, G. Majer and R. G. Barnes, Phys. Rev. B 2005, 72, 214111.

18 E. Fukushima and S. B. W. Roeder, Experimental pulse NMR: a nuts and bolts approach, Reading, MA, Addison-Wesley, 1981.

19 Z. Wu and R. E. Cohen, Phys. Rev. B, 2006, 73, 235116

20 H. Nöth and B. Wrackmeyer, In Nuclear Magnetic Resonance Spectroscopy of Boron Compounds; Springer-Verlag: New York, 
1978; pp 188, 265, 394-395; S. Heřmaánek, Chem. Rev., 1992, 92, 325.

21 L. V. Titov, E. R. Eremin and V. Y. Rosolovskii, Russ. J. Inorg. Chem. (Engl. Transl.), 1982, 27, 500; L. V. Titov, Russ. J. Inorg. Chem. (Engl. Transl.), 2003, 48, 1471.

22 S.-J. Hwang, R. C. Bowman, Jr., J. W. Reiter, J. Rijssenbeek, G. L. Soloveichik, J.-C. Zhao, H. Kabbour and C. C. Ahn, J. Phys. Chem. C, 2008, 112, 3164.

23 K. J. D. MacKenzie and M. E. Smith, Multinuclear Solid-State NMR of Inorganic Materials, London, Pergamon, 2002, pp 420-432; M. Bishop, N. Shahid, J. Yang and A. R. Barron, Dalton Trans., 2004, 2621.

24 N. Boden, in The Plastically Crystalline State, edited by J.N. Sherwood, Chichester UK, Wiley-Interscience, 1979; pp 147-214.

25 C. P. Slichter, Principles of Magnetic Resonance, Berlin, SpringerVerlag, 1978;

26 A. Abragam, The Principles of Nuclear Magnetism, Oxford, Clarendon Press, 1961.

27 W. Mandema and N. J. Trappeniers, Physica, 1974, 76, 102.

28 R. Bersohn and H. S. Gutowsky, J. Chem. Phys., 1954, 22, 651.

29 E. F. Westrum, Jr. and N. E. Levitin, J. Am. Chem. Soc., 1959, 81, 3544.

30 Y. Filinchuk, A. V. Talyzin, D. Chernyshov and V. Dmitriev, Phys. Rev. B, 2007, 76, 092104; Y. Filinchuk and H. Hagemann, Eur. J. Inorg. Chem., 2008, 3127. 